\title{
An Empirical Model for Upward Flame Spread over Vertical Flat and Corner Walls
}

\author{
CHENG OIAN and KOZO SAITO \\ Mechanical Engineering Department \\ University of Kentucky \\ Lexington, KY 40506-0108 USA
}

\begin{abstract}
The characteristics and heat transfer mechanisms of flame spread along vertical corner walls have been studied experimentally. An infrared (IR) imaging system was applied to measure the pyrolysis height during flame spread. The total incident heat flux to the wall surface from the flame was measured by Gardon-type heat flux meters. Flame height was recorded by a video camera. Based on these experimental studies and literature review, two important correlations have been found for both vertical flat wall and corner wall flame spread: (1) Flame heights are primarily proportional to the elapsed time to the power of 1.3 , even for the flame on the corner wall which is almost twice higher than the flame on the flat wall. (2) Heat flux correlates with the normalized height $\mathrm{x} / \mathrm{x}_{\mathrm{f}}$ as a power law relation with the exponent of -2.3 in preheat zone. Based on these two correlations, the transient heat flux distribution in preheat zone has been modeled as an exponential function of time and height. Introducing the heat flux model into the one-dimensional heat transfer model for preheating process, an empirical flame spread model has been developed, and verified by experimental results.
\end{abstract}

KEY WORDS: $\quad$ IR temperature measurement, upward flame spread, vertical flat and corner walls, heat flux, heat transfer, empirical power law.

\section{INTRODUCTION}

According to Emmons [1], empirical relationships play an important role in the development of fire research. Emmons states: "Mature engineering fields base their work on fundamental laws of nature combined with well verified correlated experimental data. Fire is so complex, involving interacting complex phenomena of chemistry, multicomponent fluid dynamics, heat transfer, human reactions and toxicology; thus until the advancement of the modern computer fire analysis and design was almost wholly empirical." Encouraged by Emmons' talk together 
with two motivational/inspiring works by Williams [2] and Thomas [3], we studied empirical relationships in upward flame spread, the topic widely studied by others as well [4-18]. Our intention is to experimentally find power law relations and understand physics behind them.

Upward flame spread on vertical surfaces is a critical aspect for the hazardous growth of an enclosure fire. Past studies, both experimental and theoretical, have focused on the upward flame spread over a vertical flat wall, where two-dimensional flame behavior is usually observed and a one-dimensional spread rate model is applicable with reasonable accuracy $[9,12]$. In these studies, the heat flux distribution was usually assumed to be constant up to the flame height and then be zero beyond. Under this assumption, the transient nature of the heat flux mainly relies on the variation of the flame height with time. This approach significantly simplifies the heat transfer analysis and was approved applicable to the flame spread on a vertical flat wall. The modeling of upward flame spread on a vertical corner wall, however, requires additional considerations due to the highly transient, threedimensional nature of the fire induced flow, which leads to a complex convective and radiative heat transfer to the corner wall [13].

The experimental measurement has revealed that the heat flux from the flame to the wall surface varies strongly with both height and time, especially in the preheating period. The circumstances are different for corner wall fires due to the 3D triangle configuration of the flame (as shown in Figure 1), the effects from the other side wall flame, and the much stronger fire-induced flow confined by a corner wall. Hence, it is necessary to estimate the heat flux as a function of both the elapsed time $t$, and the height location $x$. In this study, the flame spread on a vertical flat wall has also been examined, and included in the prediction model developed as a special case.

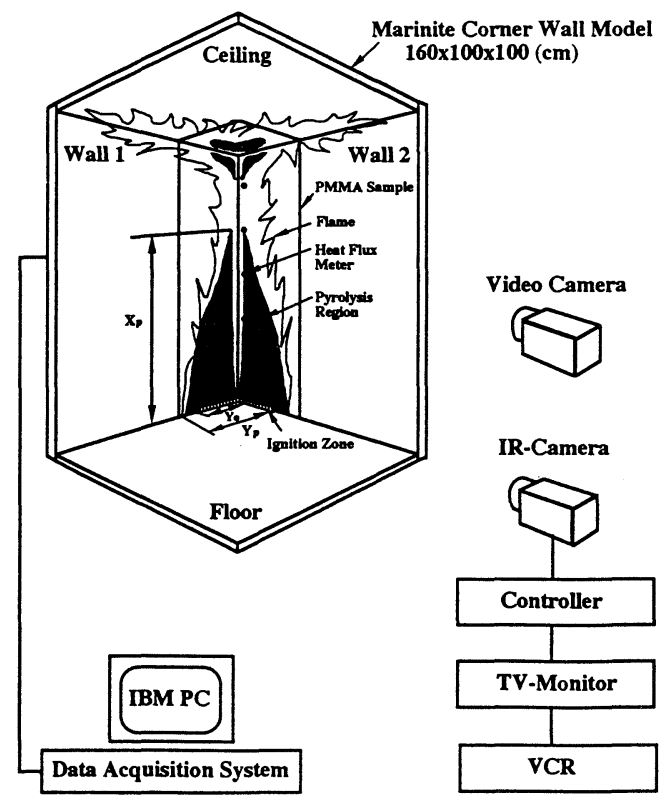

Figure 1 A schematic of experimental apparatus, flame shape and pyrolysis region visualized by IR system. Here, $\mathrm{X}_{\mathrm{p}}$ : pyrolysis height, $\mathrm{Y}_{\mathrm{p}}$ : pyrolysis width, and $\mathrm{Y}_{\mathrm{O}}$ : Ignition length. 


\section{CORNER WALL-FIRE EXPERIMENT}

A schematic of the corner wall flame spread test apparatus is shown in Figure 1. The room corner scale-model with ceiling and floor is made of Marinite boards fixed on a steel frame. Its dimensions are $1.6 \mathrm{~m}$ high $\times 1.0 \mathrm{~m}$ wide $\times 1.0 \mathrm{~m}$ long. Polymethymetharylate board (PMMA, $12.7 \mathrm{~mm}$ thick) samples were flush mounted on the corner walls and the ceiling. Ignition was provided at the bottom of both side walls by a small propane torch. The sample was assumed as thermally thick with no burn-out during flame spread. When the peak of the pyrolysis front reached the top of the sample, the flame was extinguished by a sudden purge by $\mathrm{CO}_{2}$. During flame spread, the two-dimensional spreading pyrolysis front was detected by tracing the isotherm of $T_{i g}$ using the automated IR imaging measurement system [13]. It is assumed that the pyrolysis front reaches a point exactly when the surface temperature at that point reaches ignition temperature, $\mathrm{T}_{\mathrm{ig}}$. The infrared camera was located about 7.0 meters away from the burning walls, and it can acquire the whole thermal image of the walls and the ceiling with the field of view of $15 \mathrm{deg}$. vertical x $20 \mathrm{deg}$. horizontal. To eliminate the flame interference, which includes radiation from solid soot particles and exited gas molecules, a $10.8 \pm 0.5 \mu \mathrm{m}$ band pass filter was used with the IR camera [19]. Two typical thermal images
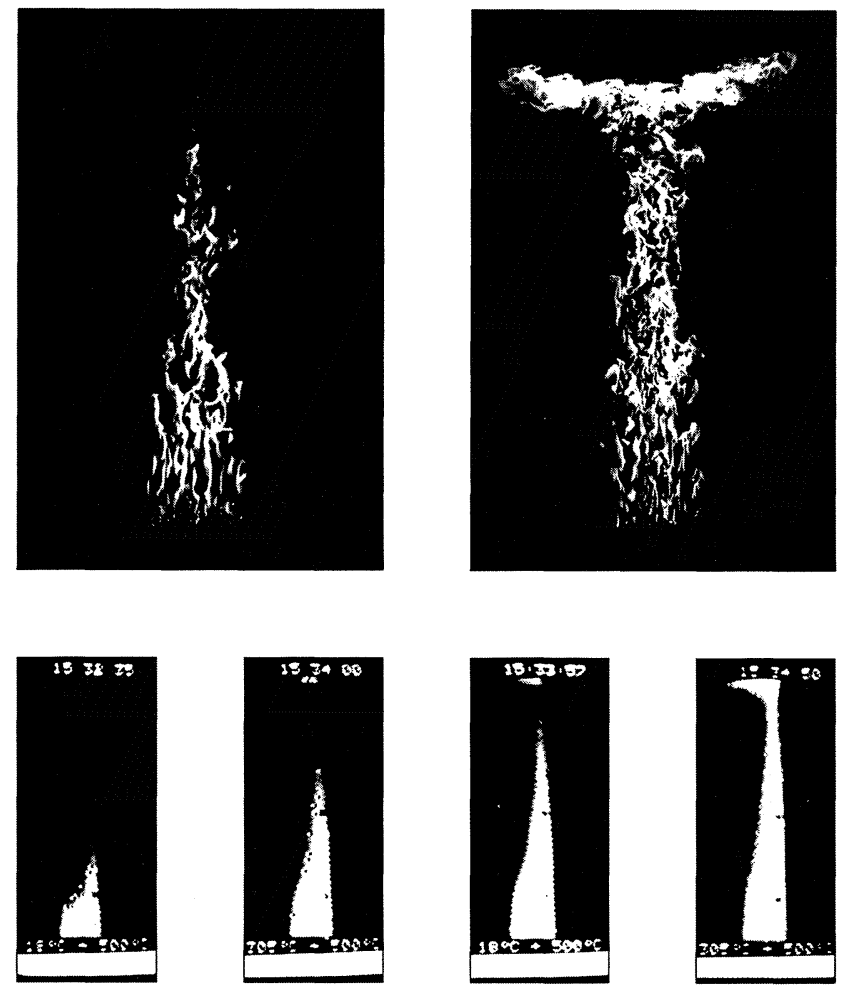

Figure 2 (a: top) Two photographs of flame spread along vertical corner walls; (b: bottom) Pyrolysis zones detected by the IR imaging system on the burning corner wall-surface at four different time periods (for the details, see $[13,19]$ ). 
of the pyrolysis zone are shown in Figure $2 b$. It was found that the flame spread rate over commonly used building materials can be accurately measured by the IR camera system [13]. During the test, the visible flame shape was simultaneously recorded by a video camera on a VHS tape as shown in Figure $2 \mathrm{a}$, from which a time averaged visible flame height was deduced. Based on the pyrolysis front measurements, total heat flux histories at those points along the trajectory of the pyrolysis front peak were measured by water cooled Gardon-type heat flux sensors, with automatic data recording and storage on a computer disc.

\section{EXPERIMENTAL RESULTS AND MODEL DEVELOPMENT}

Based on the experimental results of the flame height, and the heat flux, a thermal model for the corner fire spread will be developed using a one-dimensional heat transfer model. The predicted pyrolysis height by this model will be compared with the measured pyrolysis height. In the model development, the pyrolysis height, flame height and preheat zone are defined in Figure $3 \mathrm{a}$; the heat flux distribution, wall surface and interior temperature are depicted in Figure $3 \mathrm{~b}$ and $\mathrm{c}$. The modeling of flame spread can be conceptually divided into two parts: (1) the determination of the flame spreading velocity $v_{p}$ at a specified surface flux distribution $\dot{q}^{\prime \prime}(x, t)$; and (2) the modeling of $\dot{q}^{\prime \prime}(x, t)$ for a given flame spread. Because the power law relations are widely used to model the transient processes of flame spread, its past applications and limitations will be discussed first.

\section{(1) Power-Law Relation and Its Limitations}

The upward flame spread accelerates with time. It was also found that the pyrolysis height and the flame height increase exponentially with time in the past study [6]. Therefore, the flame height $\mathrm{x}_{\mathrm{f}}$ and pyrolysis height $\mathrm{x}_{\mathrm{p}}$ can be correlated with the spread time $t$ by power law relations, and the power law relations between $\mathrm{x}_{\mathrm{f}}, \mathrm{v}_{\mathrm{p}}$ and $\mathrm{x}_{\mathrm{p}}$ can be deduced. For example, Orloff et al. [6] obtained the results: $x_{f}=5.346 x_{p}{ }^{0.781}$ and $v_{p}=0.00441 x_{p}{ }^{0.964}$ in their exploratory study of the flame spread on PMMA vertical flat wall. Carefully examining their results, we found that the power law relations could sometimes encounter a singularity problem when one relation is used to deduce another one by taking differentials. If we assume:
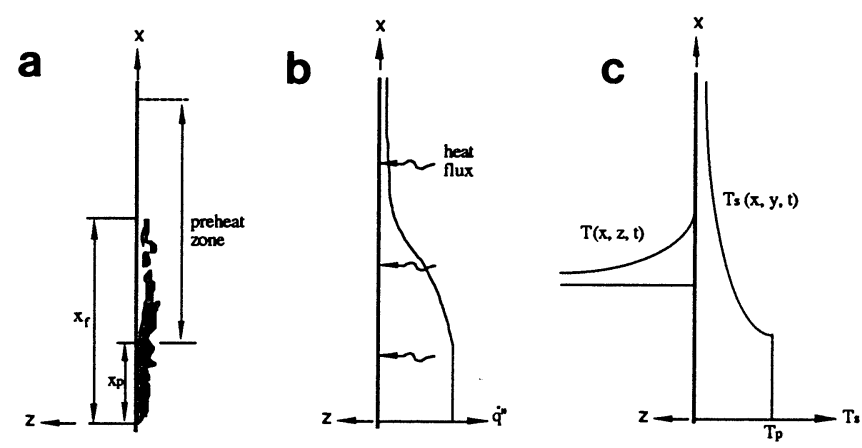

Figure 3 Schematics of flame spread on corner walls:

(a) Flame configuration, (b) Heat flux distribution, and

(c) Wall surface and internal temperature distributions. 
$\mathrm{x}_{\mathrm{p}}=\mathrm{At}^{\mathrm{m}}$

then, by the definition of the spread rate,

$v_{p}=\frac{d x_{p}}{d t}=A m t^{m-1}=\frac{A m}{A^{\frac{m-1}{m}}} x_{p}^{\frac{m-1}{m}}$.

If we correlate $\mathrm{v}_{\mathrm{p}}$ and $\mathrm{x}_{\mathrm{p}}$ directly from the experimental data, we can obtain,

$v_{p}=B x_{p}{ }^{n}$

By comparing equation 3 with equation 2, we can obtain,

$B=\frac{A m}{A^{\frac{m-1}{m}}}, \quad$ and $\quad n=\frac{m-1}{m} \quad$ or $\quad m=\frac{1}{1-n}$.

We can see the last relation does not hold when $\mathrm{n}=1$. The exponent $\mathrm{n}$ could be 1 , in fact, it is very close to 1.0 for the upward flame spread. In Orloff's results above; $n=0.964$, which resulted in the exponent $\mathrm{m}=27.78$ leaving $\mathrm{x}_{\mathrm{p}}$ proportional to $\mathrm{t}^{27.78}$. This result is obviously wrong, therefore this derivation should be avoided since there is a singular point at $\mathrm{n}=1$. The cause of this singularity is that the power law relations are only empirical correlations, if there is no obvious physical meaning. It also should be noted that the coefficients and the exponents in these power relations are only valid in the experimental ranges, or in the scale of fire spread tests.

\section{(2) Correlations of Flame and Pyrolysis Heights}

Flame height is usually considered as a characteristic length for the heat transfer from the flame to the wall surface, since the scale of the luminous chemical reaction zone dominates radiation and convection heat transfer. The past studies $[8,10]$ also found that the heat flux correlation is sustained with the normalized location height by the flame height: $\mathrm{x} / \mathrm{x}_{\mathrm{f}}$. Therefore, it is an important step to model the flame height for the heat flux modeling.

In flame spread tests, the flame height was recorded by a video camera and measured on playback screen. Results assembled from three tests with ignition lengths of 20, 30 and 40 $\mathrm{cm}$ for corner fires are shown in Figure 4. The vertical flame spread rate increases with increasing ignition length up to $20 \mathrm{~cm}$ [13]. It was observed that the laminar to turbulent transition occurred as the flame height reached about $15 \mathrm{~cm}$, and a fully developed turbulent flame was found over the height of $25 \mathrm{~cm}$. For the turbulent flame, from the height of 25 to $160 \mathrm{~cm}$, the flame height can be fitted by a power relation of time with the exponent of 1.31 , and the correlation coefficient is 0.98 . Interestingly, the flame height on a flat vertical wall of the similar scale, even almost $50 \%$ lower than the corner fire flame, can also be fitted by a power law with approximately the same exponent of 1.30 with the correlation coefficient of 0.983 , as shown in Figure 4. The flame height data for the flat wall flame spread were provided by Saito's experiments [9]. The analysis shows that the flame height for an upward turbulent flame spread, over the size range of interest here, can be represented by: 
The constant coefficient $\mathrm{C}$ is 0.094 for the corner fire, and 0.051 for the flat wall fire. This flame height model can be further confirmed as a general relation by the following analysis. The flame height has been studied extensively due to its importance $[7,8,10]$. One representative result was given by Delichatsios [7] as:

$x_{f}=4.2\left(\frac{\dot{Q}^{2}}{\rho_{o}^{2} C_{p}^{2} T_{o}^{2} g}\right)^{\frac{1}{3}}$

where $\dot{Q}$ is the heat release rate per unit width. If the assumption of constant gasification rate is introduced, which is applicable to the pyrolysis zone for non-charring materials, then the total heat release rate is proportional to the area of pyrolysis zone. Therefore, we have the relation,

$x_{f} \propto Q^{\frac{2}{3}} \propto A^{\frac{2}{3}} \approx\left(X_{p} Y_{p}\right)^{\frac{2}{3}}$,

where the area of pyrolysis: $A=X_{p} Y_{p}$ since the pyrolysis zone can be approximated as a triangle (Figure 1). And the lateral spread is much slower than the vertical spread [13]. Hence, we can assume $Y_{p}$ constant compared with $X_{p}$ in Eq. 6. Introducing the experimental correlation: $X_{p}=0.003 t^{1.84}$ into Eq. 6 , we obtain,

$x_{f} \propto\left(X_{p} Y_{p}\right)^{\frac{2}{3}} \propto X_{p^{\frac{2}{3}}} \propto\left(t^{1.84}\right)^{\frac{2}{3}} \approx t^{1.23}$.

A good agreement can be seen between Eqs. 4 and 7. This result supports the conclusion that a power relation with the exponent of 1.3 can serve as a general model for the flame height.

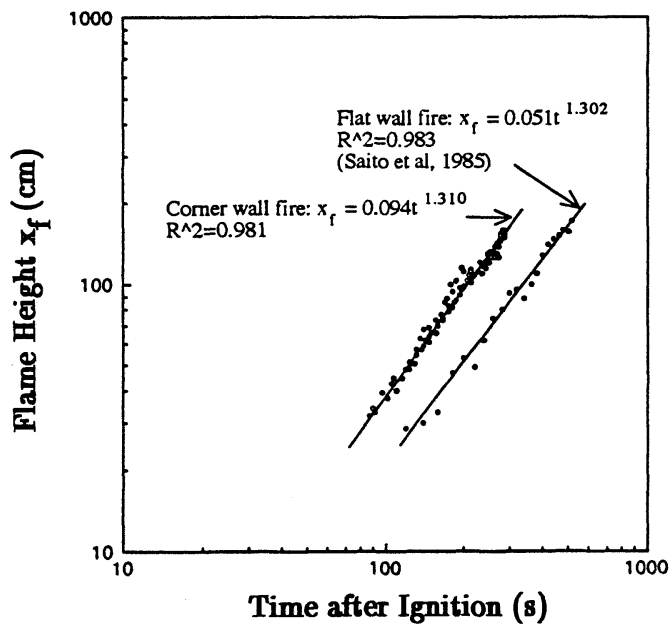

Figure 4 Comparison of visible flame height as a function of time for spreading flame over vertical flat and corner walls. 
The measured wall heat flux histories at five different locations are presented in Figure 5 (dots). These measurement points were distributed along the trajectory of the flame spread peak as indicated in Figure 1. In the preheat period, the experimental results display an increasing heat flux with time, and then the heat flux approaches to a maximum and nearly constant value of $32.5 \mathrm{~kW} / \mathrm{m}^{2}$ when the pyrolysis occurs.

From these results, spatial heat flux distributions at different moments, which correspond to the different flame heights, can be deduced. From the past studies, it was thought appropriate to scale the height $\mathrm{x}$ with the flame height $\mathrm{x}_{\mathrm{f}}$ in considering the heat flux distribution. Such a process was performed by Hasemi [10] for $\mathrm{CH}_{4}$ line burner fires against a wall with the heat released rate ranging from 10 to $100 \mathrm{~kW} / \mathrm{m}$. The same method was applied to the wall heat flux analysis for the steady burning of vertical walls made of variety of materials in Quintiere's study [8]. The corner wall heat flux distribution plotted as a function of $\mathrm{x} / \mathrm{x}_{\mathrm{f}}$ is shown in Figure 6.

Compared with Hasemi and Quintiere's results $[8,10]$, some common and important characteristics can be drawn: (i) The normalized height $\mathrm{x} / \mathrm{x}_{\mathrm{f}}$ does correlate the heat flux data for both flat wall and the corner wall fires; (ii) Heat flux distributions are nearly the same regardless of materials; and (iii) The levels of heat flux are similar for the flat wall fires, around $25 \mathrm{~kW} / \mathrm{m}^{2}$, while for the corner wall fire, the heat flux can reach $32.5 \mathrm{~kW} / \mathrm{m}^{2}$. The higher heat flux value is contributed to the corner fire configurations [13]. These results display that the wall heat flux seems to have an approximately universal distribution when plotted with the normalized height $\left(\mathrm{x} / \mathrm{x}_{\mathrm{f}}\right)$. For the preheat period in the corner fire, that corresponds to the downward-extending leg in Figure 5, the heat flux can be fitted by a power relation: $\dot{q}^{\prime \prime}=0.822\left(x / x_{f}\right)^{-2.294} \approx 0.822\left(x / x_{f}\right)^{-2.3}$ with the correlation coefficient of 0.926. In Mitler's study [12], it was shown that the power law relation with the exponent of -2.3 holds for most of the flat wall fires. In the Hasemi's result above, the exponent equals to -2.5 , which is fairly close to -2.3 considering both are empirical coefficients. Therefore, a heat flux model for the preheating zone can be formulated as:

$\dot{q}^{\prime \prime}=D\left(\frac{x}{x_{f}}\right)^{-2.3}$

Introducing the flame height model Eq. 4 into Eq. 8, we have

$\dot{q}^{\prime \prime}=D\left(\frac{x}{C t^{1.3}}\right)^{-2.3}=E x^{-2.3} t^{2.99} \approx E x^{-2.3} t^{3}$,

where $\mathrm{C}, \mathrm{D}$ are constants respectively related to the flame height and the maximum heat flux, and $\mathrm{E}=\mathrm{D} / \mathrm{C}^{-2.3}$. Equation 9 can be used for the vertical flat wall and corner wall fires. The wall heat flux calculated by Eq. 9 was plotted (solid lines) and compared with the experiment in Figure 4 resulting in a very good agreement for medium heights $(50<x<100 \mathrm{~cm})$. In the beginning and the last phase, the difference of heat flux distribution may have contributed to 
the effects of the floor and the ceiling. Considering the preheat history in the flame spread problem, however, the integration of the heat flux from Eq. 9 versus time can be expected even better in agreement with the practical case.

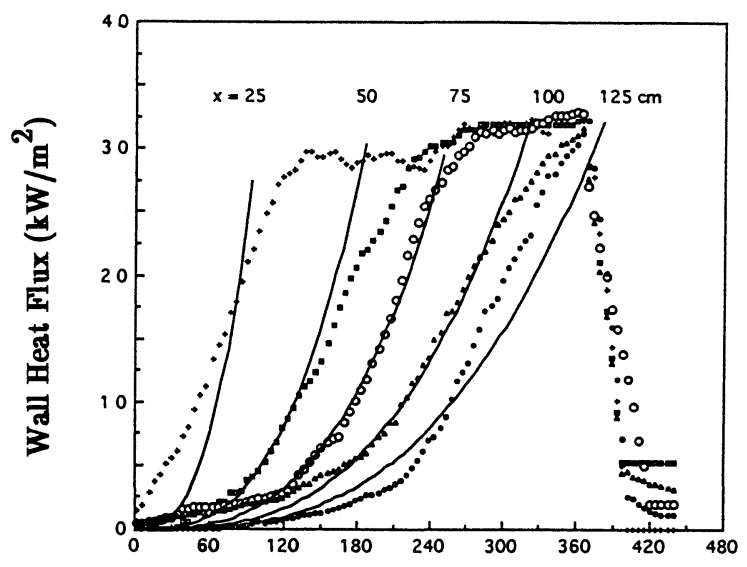

Figure 5 Comparison of heat flux model of Eq. 15 with experimental data. Solid lines are calculations by Eq. 15 at five different heights.

\section{Time after Ignition (s)}

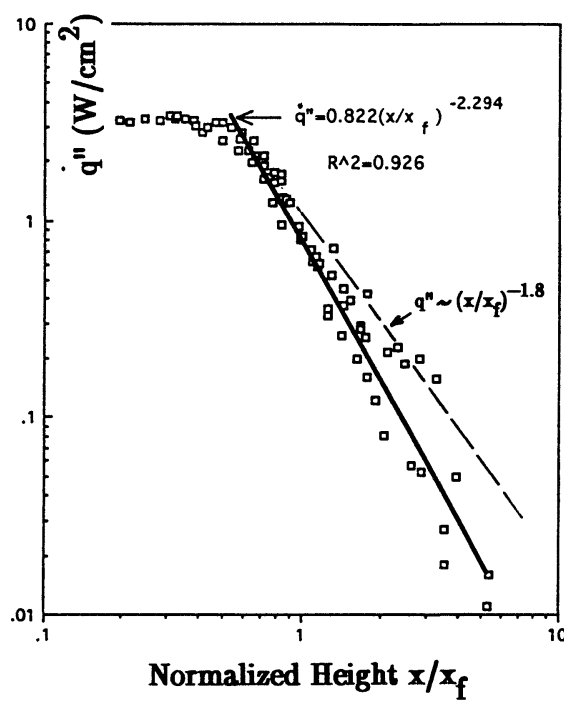

Figure 6 Heat flux distributions on a vertical corner wall as a function of the normalized flame height.

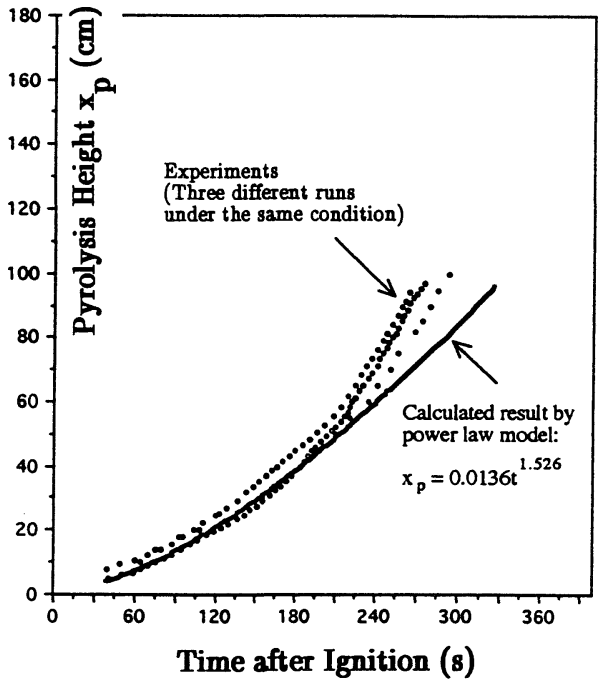

Figure 7 Comparison of the Eq.15 model with experimental data. 


\section{(4) A Thermal Model for the Flame Spread}

Upward flame spread occurs as a consequence of heating the unignited portion of the fuel to a temperature at which the vigorous pyrolysis begins. In general, we assume that the pyrolysis front reaches a point $\mathrm{x}_{\mathrm{p}}$ exactly when the surface temperature at that height reaches the pyrolysis temperature of the wall material, $T_{p}$. It is assumed that the thermophysical properties, $k, \rho$ and $\mathrm{c}$ of the material are independent of temperature. For a semi-infinite solid, the heat flux $\dot{q}^{\prime \prime}(x, t)$ at $\mathrm{z}=0$ (see Figure $3 \mathrm{~b}$ ) is a prescribed function of time and height, and the initial temperature $T_{a}$ is the ambient temperature. Then it can be shown [20] that the surface temperature $T_{s}$ is given by

$T_{s}(x, t)=T_{a}+\frac{1}{\sqrt{\pi k \rho c}} \int_{0}^{t} \frac{\dot{q}^{\prime \prime}(x, \tau)}{\sqrt{t-\tau}} d \tau$.

Let $T_{s}$ equal to $T_{p}$, $x$ equal to $x_{p}$, Eq. (10) can be written as:

$\int_{0}^{t} \frac{\dot{q}^{\prime \prime}\left(x_{p}, \tau\right)}{\sqrt{t-\tau}} d \tau-\sqrt{\pi k \rho c}\left(T_{p}-T_{a}\right)=0$

Equation 11 is the basis for the thermal model. Although this equation is practically useful, it has some limitations since a number of assumptions have been made for simplification. The heat transfer in the preheat zone was modeled as one-dimensional heat transfer. The lateral heat transfer has been neglected due to the approximately uniform heat conduction in vertical direction, and a minor heat conduction in horizontal direction. The uniform heat conduction can be proved by the previous experimental study that revealed an almost constant surface temperature gradient along vertical direction in the preheat zone [13]. The one-dimensional simplification can provide about $90 \%$ agreement with experimental results for the pyrolysis height [21]. However, for other slower flame spreads the disagreement may be significant.

This model is for semi-infinite slabs and may not be accurate for finite thickness slabs, particularly when it gets thinner. It was found the thermally thick assumption is inaccurate for the fire on the PMMA slabs of the typically used thickness of 10 or $20 \mathrm{~mm}$ [11]. Moreover, the value, $k \rho c$ is a function of temperature for most of the fuel materials; however, it is difficult to obtain its functional relationship either by experiment or by theoretical analysis.

Introducing the heat flux model Eq. 9 into Eq. 11, we can obtain,

$\int_{0}^{t} \frac{E x_{p}^{-2.3} \tau^{3}}{\sqrt{t-\tau}} d \tau-\sqrt{\pi k \rho c}\left(T_{p}-T_{a}\right)=0$

and then solve this equation for the pyrolysis height $x_{p}$ as a function of time $t$ and the fuel material properties to obtain; 
$x_{p}=\left[\frac{E \int_{0}^{t} \frac{\tau^{3}}{\sqrt{t-\tau}} d \tau}{\sqrt{\pi k \rho c}\left(T_{p}-T_{a}\right)}\right]^{0.435}$,

where $\int_{0}^{t} \frac{\tau^{3}}{\sqrt{t-\tau}} d \tau=\frac{96}{105} t^{\frac{7}{2}}$ by an integral relation. At last, the predicted pyrolysis height by this model yields:

$x_{p}=\frac{0.962 D^{0.435}}{C^{0.566}(\pi k \rho c)^{0.217}\left(T_{p}-T_{a}\right)^{0.433}} t^{1.523}$,

where $\mathrm{C}$ and $\mathrm{D}$ are constants from Eq. 4, Eq. 8, and $\mathrm{x}_{\mathrm{p}}$ is in centimeter and $\mathrm{t}$ in second.

Applying PMMA corner fire test data, $\mathrm{T}_{\mathrm{p}}=376^{\circ} \mathrm{C}, \mathrm{T}_{\mathrm{a}}=20^{\circ} \mathrm{C}$ and $k \rho \mathrm{c}=0.01$ $\left(\mathrm{W} / \mathrm{cm}^{2} \mathrm{~K}\right)^{2}$ s to Eq. 14, pyrolysis height $\mathrm{x}_{\mathrm{p}}$ can be obtained as:

$x_{p}=0.0136 t^{1.526}$.

Equation 15 is compared to experimental results in Figure 7, a very good agreement was found for the early period, and a poor agreement for the later period. The reason for the disagreement was thought to be the failure of thermally thick assumption.

\section{CONCLUSIONS}

(1) Based on the experimental study of flame spread characteristics, and heat transfer mechanisms of corner fires, an empirical model for the upward flame spread has been developed. The model includes three parts: the flame height correlation, the heat flux model and the heat conduction preheating model.

(2) Although the acceleration process of flame spread is not necessarily exponential, a good approximation can be provided by the power law relations. Great care should be taken in deducing these empirical relations mathematically when the lack of the physics is evident. Flame height for the flat wall and the corner wall fires is primarily proportional to the elapsed time to the 1.3 power, even the flame on the corner wall is almost twice higher than the flame on the flat wall. This conclusion is basically consistent with the previous finding that the flame height is proportional to the energy release rate to the $2 / 5$ power. The transient heat flux tends to have an universal distribution when plotted with the vertical distance normalized by the instant flame height $\left(\mathrm{x} / \mathrm{x}_{\mathrm{f}}\right)$. By correlating the experimental data, the heat flux in preheating period can be modeled by a power relation which includes the time $t$ to the power 3 and the height $x$ to the power -2.3 . This formulation is valid for both vertical corner wall and flat wall fires, and also includes the steady state wall fire heat flux distribution model as a special case when the time, $t$ is constant. This heat flux model is less satisfactory in low and high portions of the corner wall where the floor and ceiling effects on the flame spread are significant. But the overall agreement with experiments is acceptable. 
(3) The preheating process of fuel can be simulated by the one-dimensional heat conduction model in a semi-infinite solid, which is exposed to a variable heat flux. A thermal model for vertical flame spread has been established by applying the transient heat flux model to the heat conduction model. The agreement of this model prediction with experimental measurement of pyrolysis height in corner fire has been confirmed.

(4) The results of this study hold for the turbulent room fires, while for the small scale fires where laminar flame dominates heat transfer and large wall fires where flame radiation dominates the heat flux, these correlations and models should begin to fail.

\section{ACKNOWLEDGEMENT}

This study was supported in part by NIST under Grant No. 60NANB2D1295, in part by the Center for Manufacturing Systems of the University of Kentucky, and in part by KentuckyNASA EPSCoR program.

\section{REFERENCES}

1. Emmons, H.W., "The New Fire Engineering", presented at the William Maxwell Reed seminar, Mechanical Engineering Department, University of Kentucky, Lexington, KY 40506, March, 1992.

2. Williams, F.A., "Scale Modeling of Combustion Phenomena", a Key Note Lecture at the $\underline{2}^{\text {nd }}$ International Symposium on Scale Modeling, 1997.

3. Thomas, P.H., "Fire, Flames and Dimensional Analysis", Howard Emmons Invited Plenary Lecture, Fire Safety Science - Procs. Third International Symposium, Elsevier Applied Science, London, 1991, pp. 3-26.

4. Fernandez-Pello, A.C. and Hirano, T., Combustion Science and Technology, 32: 1-31 (1983).

5. Hirano, T. and Saito, K., Progress in Energy and Combustion Science, 20: 461-485 (1994).

6. Orloff, L., deRis, J. and Markstein, G.H., "Upward Turbulent Fire Spread and Burning of Fuel Surface", Fifteenth Symposium (International) on Combustion, The Combustion Institute, Pittsburgh, pp. 183-192 (1975).

7. Delichatsios, M.A., Orloff, L., and Delichatsios, M.M., "The Effects of Fuel Sooting Tendency and The Flow on Flame Radiation in Luminous Jet Flames", Combustion Science and Technology, 84:199-215 (1984).

8. Quintiere, J.G., Harkleroad, M., and Hasemi, Y., "Wall Flames and Implications for Upward Flame Spread", Combustion Science and Technology, 48:191-222 (1986). 
9. Saito, K., Quintiere, J.G., and Williams, F.A., "Upward Turbulent Flame Spread", Fire Safety Science - Proc. First International Symposium, Hemisphere Publishing Corp., 1985, pp. 75-86.

10. Hasemi, Y., "Thermal Modeling of Upward Wall Flame Spread", Fire Safety Science Proc. First International Symposium, 1985, pp. 87-96.

11. Kulkarni, A.K. and Kim, C.I., "Heat Loss to the Interior of a Free Burning Vertical Wall and Its Influence on Estimation of Effective Heat of Gasification", Combustion Science and Technology, 73:493-504 (1990).

12. Mitler, H., "Predicting the Spread Rates on Vertical Surfaces", Twenty-Third Symposium (International) on Combustion, The Combustion Institute, 1990, pp. 1715-1721.

13. Qian, C., Ishada, H., and Saito, K., "Upward Flame Spread along PMMA Vertical Corner Walls, Part II: Mechanism of M-shaped Pyrolysis Front Formation", Combustion and Flame, 99:331-338 (1994).

14. Cleary, T.Q. and Quintiere, J.G., "A Framework for Utilizing Fire Property Tests", Fire Safety Science - Procs. Third International Symposium, Elsevier Applied Science, London, 1991, pp. 647-656.

15. Williamson, R.B., Revenaugh, A. and Mowrer, F.W., "Ignition Sources in Room Fire Tests and Some Implications for Flame Spread Evaluation", Fire Safety Science - Procs. Third International Symposium, Elsevier Applied Science, London, 1991, pp. 657-666.

16. Karlsson, B. and Magnusson, S.E., "Combustible Wall Lining Materials: Numerical Simulation of Room Fire Growth and the Outline of a Reliability Based Classification Procedure", Fire Safety Science - Procs. Third International Symposium, Elsevier Applied Science, London, 1991, pp. 667-678.

17. Newman, J.S. and Tewarson, A., "Flame Spread Behavior of Char-Forming Wall/Ceiling Insulating Materials", Fire Safety Science - Procs. Third International Symposium, Elsevier Applied Science, London, 1991, pp. 679-688.

18. Beck, V.R. and Yung, D., "The Development of a Risk-Cost Assessment Model for the Evaluation of Fire Safety in Buildings", Fire Safety Science - Procs. Fourth International Symposium, The International Association for Fire Safety Science, 1995, pp. 817-813.

19. Arakawa, A., Saito, K., and Gruver, W.A., "Automated Infrared Imaging Temperature Measurement with Application to Upward Flame Spread Studies, Part I", Combustion and Flame, 92:222-230 (1993).

20. Carslaw, H.S. and Jaeger, J.C., Conduction of Heat in Solids, $2^{\text {nd }}$ ed., Oxford (1959).

21. Qian, C. and Saito, K., Progress in Energy and Combustion Science, 1996, submitted. 